DOE/MC/29061-96/C0676

$$
\text { CONF-9510109--40 }
$$

Bond Strength and Stress Measurements in Thermal Barrier Coatings

Author:

Maurice Gell

Eric Jordan

Contractor:

South Carolina Energy Research and Development Center

Clemson University

Clemson, SC 29634

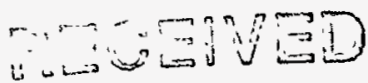

A

OSTI

Contract Number:

DE-FC21-92MC29061

Subcontract No. 94-01-SR030

Conference Title:

Advanced Turbine Systems Annual Program Review

Conference Location:

Morgantown, West Virginia

Conference Dates:

October 17-19, 1995

Conference Sponsor:

U.S. Department of Energy, Office of Power Systems Technology, Morgantown Energy Technology Center

Contracting Officer Representative (COR):

Norman Holcombe

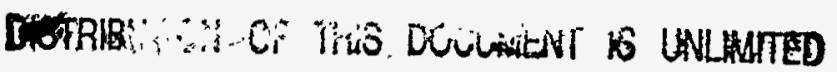




\section{Disclaimer}

This report was prepared as an account of work sponsored by an agency of the United States Government. Neither the United States Government nor any agency thereof, nor any of their employees, makes any warranty, express or implied, or assumes any legal liability or responsibility for the accuracy, completeness, or usefulness of any information, apparatus, product, or process disclosed, or represents that its use would not infringe privately owned rights. Reference herein to any specific commercial product, process, or service by trade name, trademark, manufacturer, or otherwise does not necessarily constitute or imply its endorsement, recommendation, or favoring by the United States Government or any agency thereof. The views and opinions of authors expressed herein do not necessarily state or reflect those of the United States Government or any agency thereof.

This report has been reproduced directly from the best available copy.

Available to DOE and DOE contractors from the Office of Scientific and Technical Information, 175 Oak Ridge Turnpike, Oak Ridge, TN 37831; prices available at (615) 576-8401.

Available to the public from the National Technical Information Service, U.S. Department of Commerce, 5285 Port Royal Road, Springfield, VA 22161; phone orders accepted at (703) 487-4650. 


\title{
Bond Strength and Stress Measurements in Thermal Barrier Coatings
}

\author{
Maurice Gell (860-486-3514) \\ Dept. of Metallurgical Engineering and Institute of Materials Science \\ Eric Jordan (jordan@eng2.uconn.edu; 860-486-2371) \\ Dept. of Mechanical Engineering \\ University of Connecticut \\ Storrs, CT 06269
}

\section{Introduction}

Thermal barrier coatings have been used extensively in aircraft gas turbines for more than 15 years to insulate combustors and turbine vanes from the hot gas stream. Plasma sprayed thermal barrier coatings (TBCs) provide metal temperature reductions as much as $300^{\circ} \mathrm{F}$, with improvements in durability of two times or more being achieved. The introduction of TBCs deposited by electron beam physical vapor deposition (EB-PVD) processes in the last five years has provided a major improvement in durability and also enabled TBCs to be applied to turbine blades for improved engine performance. To meet the aggressive Advanced Turbine Systems goals for efficiency, durability and the environment, it will be necessary to employ thermal barrier coatings on turbine airfoils and other hot section components. For the successful application of TBCs to ATS engines with $2600^{\circ} \mathrm{F}$ turbine inlet temperatures and required component lives 10 times greater than those for aircraft gas turbine engines, it is necessary to develop quantitative assessment techniques for TBC coating integrity with time and cycles in ATS engines.

Thermal barrier coatings in production today consist of a metallic bond coat, such as an

Research sponsored by U. S. Department of Energy's Morgantown Energy Technology Center, under Contract \# 95-01-SR030 with University of Connecticut, Storrs, Connecticut - 06269 .
MCrAlY overlay coating or a platinum aluminide ( $\mathrm{Pt}-\mathrm{Al})$ diffusion coating. During heat treatment, both these coatings form a thin, tightly adherent alumina $\left(\mathrm{Al}_{2} \mathrm{O}_{3}\right)$ film. The ceramic layer, usually 5 to 10 mils of yttria stabilized zirconia, is applied over the alumina film by plasma spray or EB-PVD processes.

Failure of TBC coatings in engine service occurs by spallation of the ceramic coating at or near the bond coat to alumina or the alumina to zirconia bonds. Thus, it is the initial strength of these bonds and the stresses at the bond plane, and their changes with engine exposure, that determines coating durability.

The purpose of this program is to provide, for the first time, a quantitative assessment of TBC bond strength and bond plane stresses as a function of engine time and cycles. This information is needed by coating suppliers to provide coatings with higher and more consistent quality. It is also needed by engine manufacturers to deterimine life remaining in service, as well as to refine fracture mechanics analyses and lifetime prediction models.

\section{Objectives}

The objectives of this program are:

1. To develop fundamental understanding of the role of residual stress and bond strength in the failure of TBC's and to use that 
understanding to guide lifetime prediction modeling and coating development.

2. To use new, innovative techniques to obtain quantitative measurements of bond strength and bond stress.

3. To make the data generated as relevant as possible by obtaining representative production coatings tested under simulated ATS conditions in furnace, rig and engine tests from coating suppliers, ATS engine developers, and national laboratories.

4. To coordinate this research with the internal TBC programs at NASA-Lewis Research Center and Oak Ridge National Laboratory; thereby enhancing the scope and depth of this work.

5. To work with ATS engine developers, so this data can be utilized in their fracture mechanics analyses and lifetime prediction models.

6. To place major research emphasis on those bond strength and stress measurement techniques that have the potential for development into non-destructive inspection techniques (NDI) for initial coating quality, and for residual life remaining on service engine components.

7. To transfer NDI techniques to coating suppliers and to ATS engine developers for determination of initial coating quality and for residual life remaining for engine components.

\section{Approach}

Based on the extensive research conducted on thermal barrier coatings (TBCs) over the last ten years [1-6], it is possible to describe three essential features to the successful performance of thermal barrier coatings. First, partially stabilized zirconia thermal barrier coatings, that have good thermal stability to $2600^{\circ} \mathrm{F}$ and good thermal expansion matching with superalloys, are intentionally processed with microstructural defects such as porosity and microcracks to reduce the through-thickness thermal conductivity of the material compared to fully dense zirconia. The lower the thermal conductivity the more effective the coating is as a thermal barrier.

Second, the partially stabilized zirconia must be bonded to the superalloy. This is accomplished with the use of a metallic bond coat, such as an MCrAlY overlay coating or a platinum aluminide diffusion coating. During heat treatment, both these coatings form a thin, tightly adherent alumina $\left(\mathrm{Al}_{2} \mathrm{O}_{3}\right)$ film (Figure 1). For plasma deposited TBCs, the bond coat surface is processed to be rough, so as to provide mechanical bonding between the bond coat and the ceramic. For EB-PVD deposited TBCs, the bond coat surface is processed to be smooth, so as to maximize chemical atomic bonding between the alumina and the zirconia. It is the strength of the bonds between the alumina and the superalloy, between the alumina and zirconia, and in the zirconia near the bond line that determines the durability of the coating in engine service.

Since the failure mechanism of thermal barrier coatings in engine service is spallation of the ceramic at or near the bond coat-zirconia interface (Figure 1), the third essential feature of thermal barrier coatings is maintaining low stresses at the bond plane. There are a number of contributors to keeping bond stresses low that include: (1) selection of a bond coat and ceramic that have a moderate thermal expansion mismatch, (2) the creation and maintenance of a microstructure with a low elastic modulus in the plane of the coating, (3) retarding the growth of the alumina film with its attendant volume expansion and increase in stress, and (4) avoiding cyclic creep rumpling of the bond coat 
with the creation of stress concentrations and additional surface area for oxide growth.

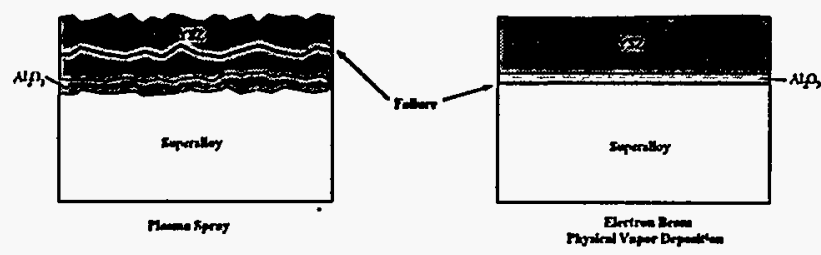

Figure 1:The layered structure and spallation location for plasma sprayed and electron beam physical vapor deposited thermal barrier coatings.

\section{Bond Strength And Stress Changes}

In plasma sprayed and EB-PVD deposited TBCs, the bond strengths in the as-coated and heat treated condition are relatively high. The relevant bonds are those that result in spallation in engine service and consist of the superalloy to alumina, the alumina to zirconia, and in the case of plasma deposited TBCs, the zirconia to zirconia bonds in the vicinity of the alumina to zirconia bond plane (Figure 1). With time and cycles in the engine, bond strength tends to degrade as a result of thermal activated interdiffusion between the various layers of the TBC coating. For example, superalloy and bond coat elements have been found on the spalled fracture surfaces of plasma and EB-PVD TBCs [4], and it is known that sulfur diffusion can markedly reduce alumina scale adhesion to superalloys [7].

In contrast, bond plane stresses are relatively low in the as-coated and heat treated condition as a result of bond coats and ceramics selected for moderate thermal expansion mismatch and because of high component temperatures during coating deposition. With time and cycles in the engine, bond plane stresses increase (Figure 2) as a result of (1) sintering of the ceramic, which increases the elastic modulus, (2) growth of the alumina film which involves a volume expansion and increased stress, and (3) "rumpling" of the bond coated resulting from cyclic plastic deformation, resulting in increased surface roughness, stress concentrations, and accelerated oxidation.

\section{Coating Spallation Model}

Thus, this state-of--the-art TBC spallation assessment indicates that bond strengths deteriorate and bond stresses increase with increased engine time and cycles. Local coating spallation occurs when the bond stress equals the bond strength (Figure 2). There are two views as to the important processes leading to that failure condition (1) coating failure is a fatigue process enhanced by residual stress effects and bond weakening or (2) failure is an overload, single cycle process. Crack propagation in ceramics is know to be an extremely sensitive function of stress intensity factor, depending for example, on the $20^{\text {th }}$ power of the stress intensity factor [8]. For such behavior, once a cracks begins growing, failure will rapidly occur. Accordingly it may be that most of the life is spent in bond strength degradation and residual stress increase. The observation of prefailure damage at 20-30 percent of the coating life consisted of linking smaller cracks [9]. It may be that the accumulating residual strain is relieved by microcracking until there is so much crack linking that spallation occurs. In this study, we will obtain sufficient information on residual stress evolution and bond strength degradation to begin to distinguish between these two hypotheses.

In summary, the three essential features of successful thermal barrier coatings are: low thermal conductivity, high bond strength, and low bond plane stresses. For a given thermal barrier coating operating in a specific thermal environment, the durability of the coating is determined by the changes in bond strength and bond stress with time and cycles in the engine, as illustrated in Figure 2. 


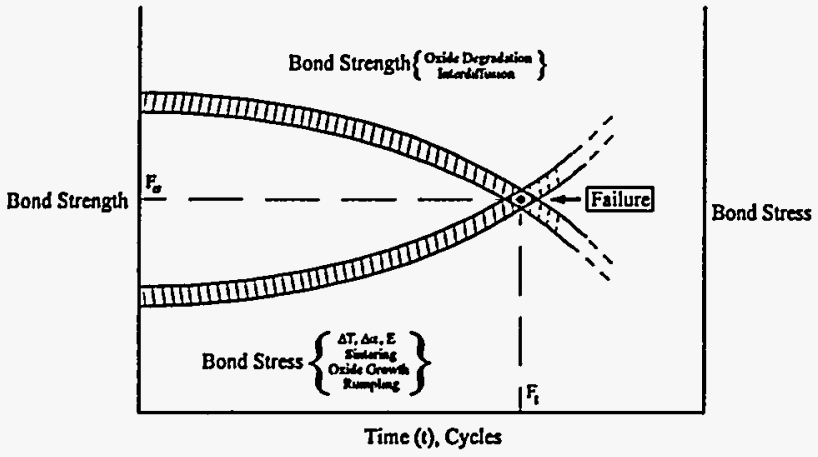

Figure 2: Coating spallation failure model based on the changes in bond strength and stress with engine cycles and time.

\section{Project Description}

In this program a number of analytical instrumental techniques, that are illustrated below, will be evaluated to quantitatively measure:

( I ) TBC bond plane stresses as a function of time by (a) enhanced laboratory $x$-ray diffraction, (b) enhanced synchrotron x-ray diffraction, (c) laser fluorescence, (d) neutron diffraction, and (e) AC potential drop measurements and

( II ) TBC bond strength by using: (a) a modified ASTM direct pull test, (b) laserinduced ultrasonics, (c) a cyclic Hertzian ball indentation test, and (d) a bend toughness test.

These tests will be conducted on current production TBC coatings, including plasma sprayed and EB-PVD deposited yttria stabilized zirconia thermal barrier coatings with both MCrAlY and Pt-Al bond coats. The specimens will be tested in a severe thermal cyclic environment, approximating ATS engine conditions.

\section{I a. Enhanced Laboratory X-ray Diffraction}

In measuring stress by $x$-ray diffraction, a single wave length $x$-ray beam is directed at a surface of interest and the diffracted intensity is measured as a function of scanning angle. Here the purpose is to measure the residual stress on the surface of the bond coat which is beneath the ceramic coating (Figure 3). Since the illuminating beam and the diffracted beam passing through the ceramic will suffer some attenuation, the following method is adopted: The wavelength of the illuminating beam is to be chosen to have a wavelength corresponding to local absorption minimum, which should be just below the zirconia absorption edge $(\approx 17$ $\mathrm{KeV}$ photon energy ). Also the intensity of the illuminating beam will be maximized by use of a Johanssen ground and bent single crystal (Figure 4). to yield a beam of $>10^{8}$ counts/sec. [10]

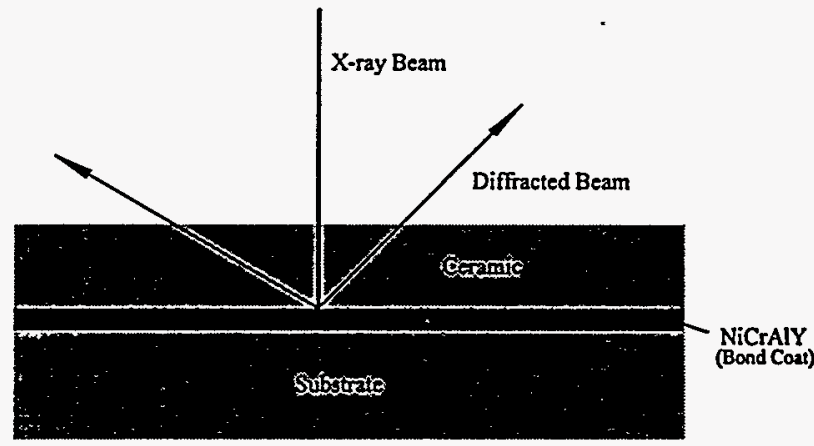

Figure 3: Schematic of a X-ray diffraction experiment on a TBC.

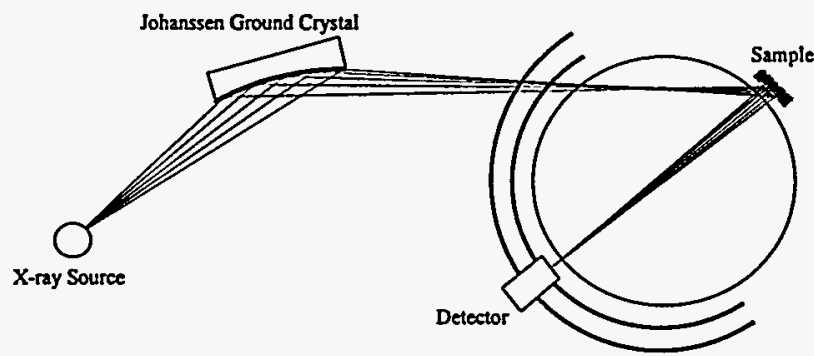

Figure 4: Enhancement of an incident $X$-ray beam using a Johanessen bent crystal.

\section{I $\underline{b}$ Enhanced Synchrotron X-ray Diffraction}

In the proposed experiments, an annular blocking slit with a large area detector behind it will be used to detect the entire diffraction cone, (Figure 5) mounted on a precision translator is to be used so that different diffraction lines may 
be selected. An increase of about 100X in the diffracted intensities compared to the usual configuration, is estimated.

The incident sagitally focused (pencil) beam with an intensity $>10^{9}$ counts/sec and having a beam size of only $1 \mathrm{~mm} \times 1 \mathrm{~mm}$ will allow one to probe point by point and explore spatial variation in the residual stress [11]

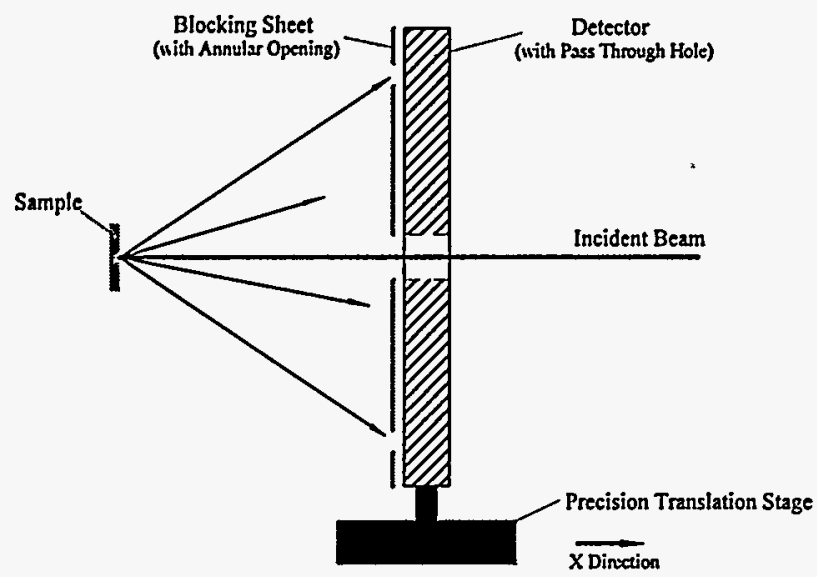

Figure 5: Schematic showing the collection of diffracted beam through an annular blocking slit.

\section{I c Laser Fluorescence}

The frequency shift in the fluorescence spectra of the alumina layer, characteristic of chromium-doped alumina, provides a means of non-destructively measuring the stress in alumina scales using the piezo-spectroscopic effect [12]. Furthermore, the broadening of the lines can be used to measure of the stress gradient. Zirconia based thermal barrier coatings (TBC) being optically translucent at certain wavelengths will be examined for the stress in the oxide scale formed on the bond coat underneath the TBC. (Figure $6 \& 7$ )

The laser fluorescence work will be performed by Prof. David Clarke of University of California, Santa Barbara.

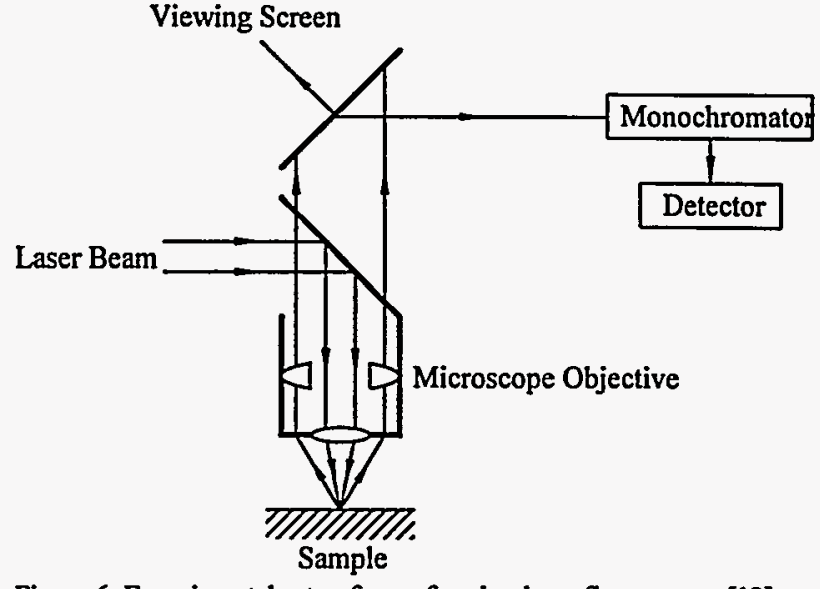

Figure 6: Experimental setup for performing laser fluoroscence[12].

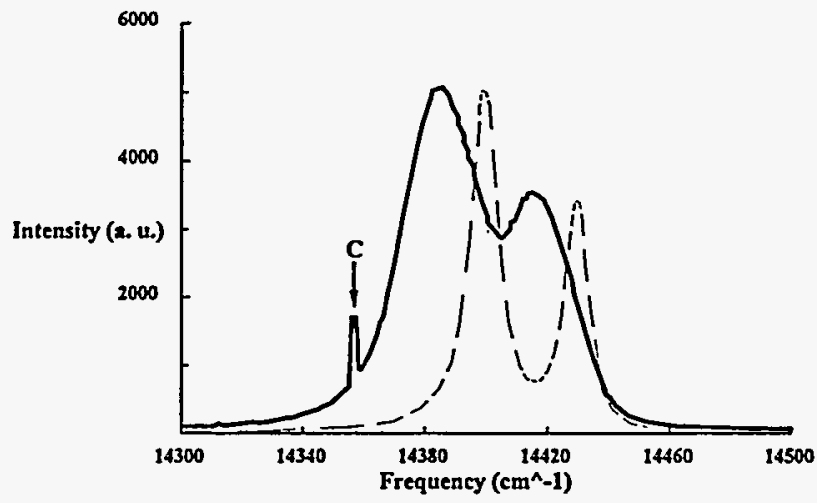

Figure 7: Spectra shows the shift in the frequency number for alumina scale under residual stress[12].

\section{I $\underline{\text { d Neutron Diffraction }}$}

Neutrons are highly penetrating and diffract according to Braggs law, based on their DeBroglie wave lengths, in a manner directly analogous to x-rays. In the proposed work, a diffractometry setup called the Intense Pulsed Neutron Source ( IPNS) (Figure 8) used for examining residual stress in subsurface fiber in composites, is to be utilized [13]. Here, the average residual stress developed at the crystallographically distinct bond coat and the alumina layer that forms at the bond coat to ceramic interface, is to be measured. The primary challenge in carrying out this technique is the relative small volume of the phases of interest (bond coat and alumina), which leads to relative few diffracted neutrons. 
Neutron diffraction measurements will be conducted at Argonne National Labs and/or at Oak Ridge National Lab.

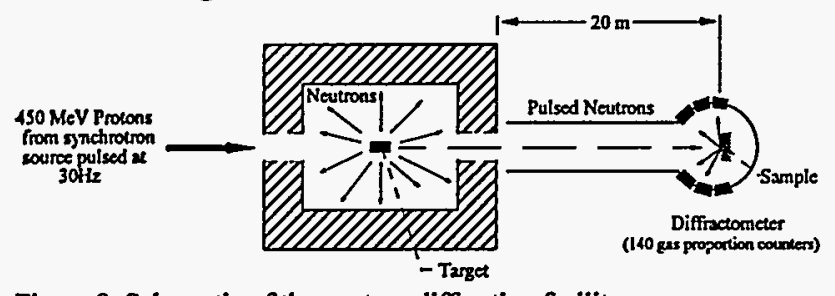

Figure 8: Schematic of the neutron diffraction facility

\section{I e AC Potential Drop}

In this technique, an alternating current is induced in the sample and a patented method is used to confine the current flow to a narrow line on the surface of the sample [14] (Figure 9). In addition to current confinement, the sensitivity of the method has been enhanced by the use of lock-in detection methods. Information is obtained as a function of depth by scanning in frequency, with the higher frequency current confined to the near surface location by the skin effect. This method has been successfully used to reliably detect small cracks in fatigue crack "initiation" experiments [15].

This work will be done by Dr. Norman Marchand of AMRA Inc.

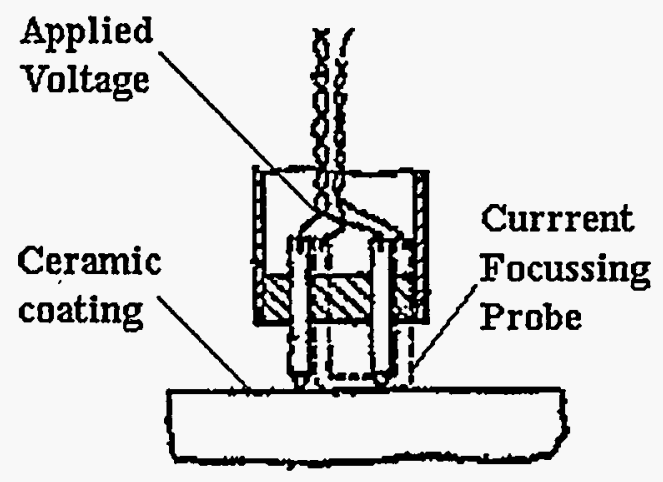

Figure 9 Schematic of $A C$ potential drop measurement technique[15].

\section{II a Modified ASTM Direct Pull Tests}

Most thermal barrier bond strength testing to date has been done using methods similar to the ASTM Standard C633-79 "Standard Test Method for Adhesion or Cohesive Strength of Flame-Sprayed Coatings" in which a coating is applied to the end of a cylindrical bar and another bar is bonded to the top surface using a polymer adhesive. The assembly is then tested in tension to fail the ceramic metal interface (Figure 10). This type of test is unfortunately not suitable for unaged coatings, because the adhesive fails first and coating interface values are not obtained [16]. However successful tests using this method were done on thermally aged samples in which the TBC bond strength was reduced. The stress state in these direct pull tests is quite complex due to mismatch in mechanical properties and due to the non uniform stress distribution caused by attachment holes [16]. A recent design improvement will be incorporated into the test system design to produce dramatically more uniform stress distribution [17]. In addition improved adhesives and adhesive processing will be employed to provide higher failure stresses.

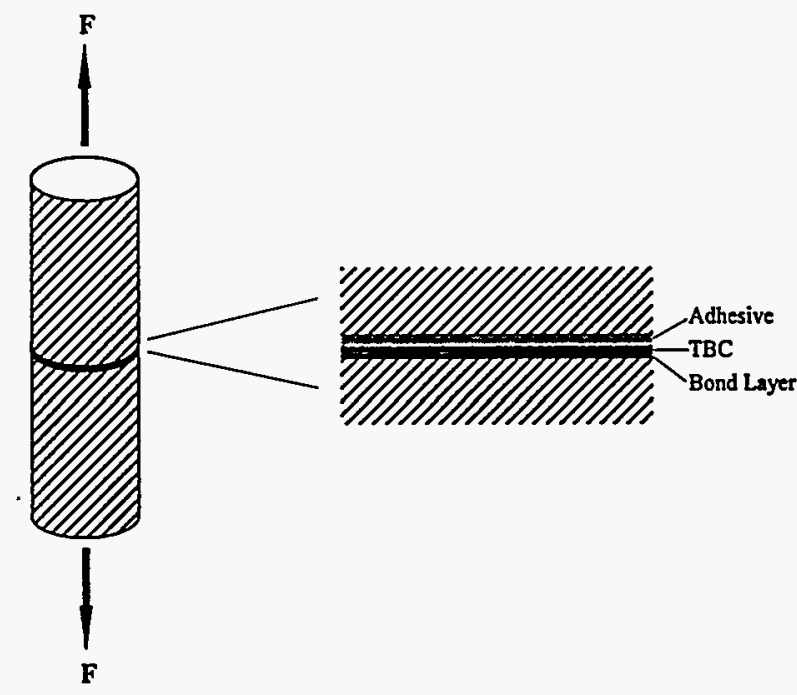

Figure 10: Blow-up of the specimen to be used for pull tests. 


\section{II $\mathrm{b}$ Laser Induced Ultrasonic Testing}

In this recently developed method of testing, a laser induced sonic pulse is used to produce coating spallation $[18,19]$. In this method a very short duration laser pulse is made to fall on a gold foil behind a quartz window (Figure. 11). The sudden heating produces an intense acoustic pulse that reflects off the free surface of the coating, producing a tensile pulse that fails the coating. The stress at the coating interface is calculated from the measured acoustic pulse. This method produces a stress state free of the undesirable effects of bending and constraint present in most other test including the ASTM test.

This work will be done by Prof. Vijay Gupta of University of California, Los Angeles.

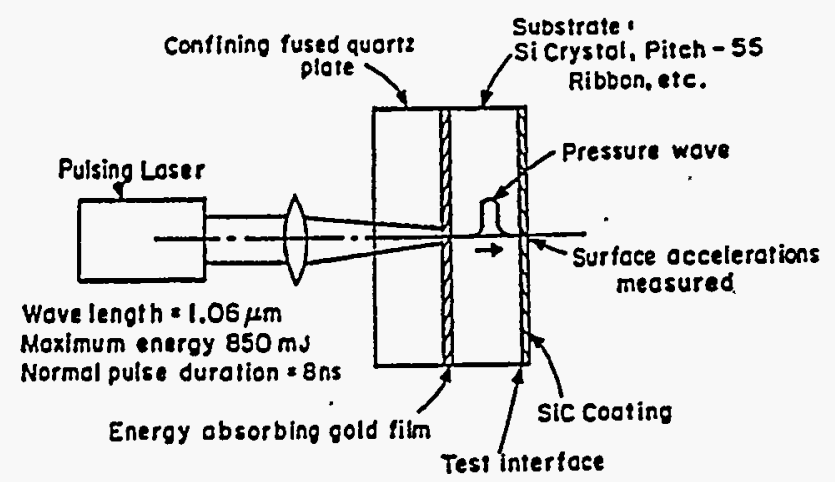

Figure 11: Illustration of coating spallation through LASER induced ultrasonic wave.[19].

\section{II $\underline{\mathrm{c} \text { Hertzian Ball Indentation Test }}$}

The Hertzian indentation test is chosen because of its ability to replicate the actual mode of failure of coatings in actual situations. Preliminary experiments have revealed that a common mode of coating failure exists between the specimens tested using the Hertzian indentation test and specimens subjected to simulated ATS engine conditions in both cases the coating failed within the ceramic but near the ceramic-bond coat interface [20]

Preliminary experiments on plasma
- sprayed coatings have suggested that during loading both coating and substrate deform elastically and plastically (Fig. 12). During unloading, due to a large amount of plasticity in the substrate and the bond coat relative to the ceramic coating, there is differential elastic recovery in the system.

This elastic recovery mismatch results in tensile stresses normal to the coating-substrate interface, and drive the delamination crack within the ceramic but near the ceramic bond coat interface (Fig. 13).

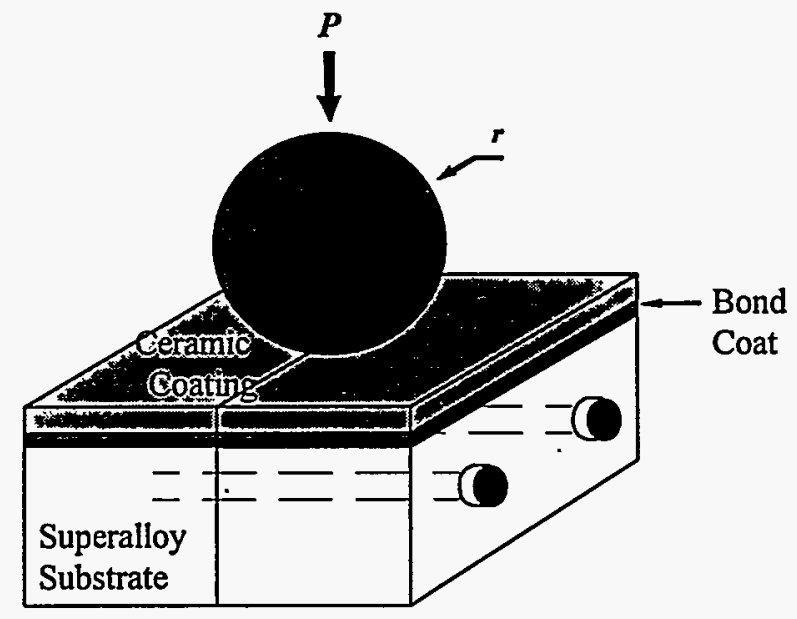

Figure 12: The Ball indendation test
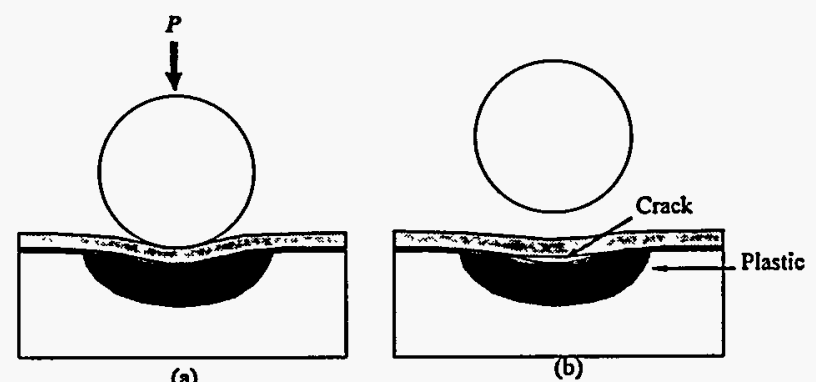

Figure 13: Plastic zone formation due to difference in the recovery rate.

\section{II d Delamination Toughness Test}

For brittle materials, the fracture strength, is directly related to their crack propagation resistance according to the well-known Griffith formula. According to the Griffith equation, measurement on the fracture energy of the 
interfacial region between the PSZ coating and the superalloy substrate reflects the strength of this interfacial region because of the brittle nature of the PSZ and PSZ/bond-coat interface. A sandwich-type chevron-notched specimen proposed by Shaw, et al. [21-23] is most attractive for our current applications. This specimen geometry can be modified to measure the bond strength between the thermal barrier coating and the superalloy substrate. The specimen consists of a thin layer (bond coat and PSZ coat) within an otherwise elastically homogeneous specimen with a chevron notch along the bond coat plane. The bonding between a superalloy block and a coated superalloy is formed through epoxy.
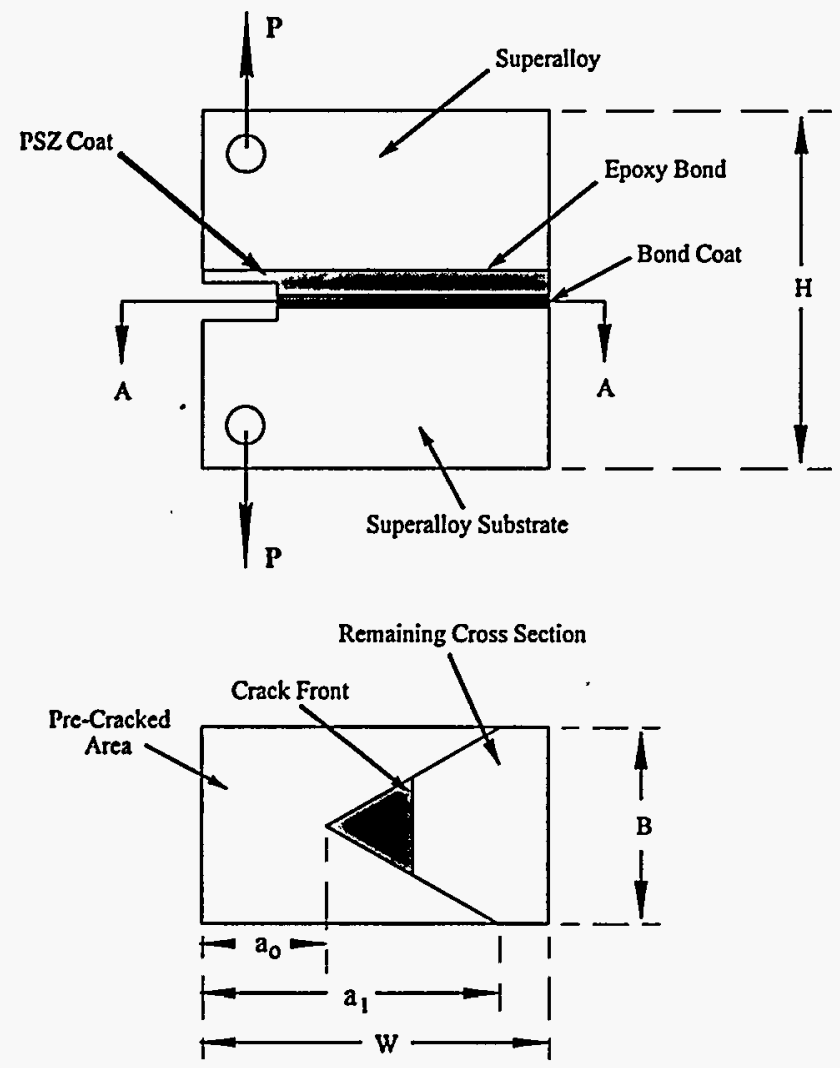

A-A

Figure 14: Sketch of the sample for delamination toughness measurements.
The chevron notch introduced only faces the PSZ/bond-coat and bond-coat/superalloy interfaces, as shown in Figure 14, to insure that the initiation and propagation of the crack is at the weakest position between the PSZ and superalloy substrate.

\section{Benefits}

The benefits of this program are to advance the state-of-the art of TBCs by providing a quantitative measurement of bond strength and bond plane stresses. These studies will be closely coordinated with ATS engine developers and coating suppliers, so that TBCs can be successfully implemented in support of ATS durability and performance goals. The results of this program will help to ensure that thermal barrier coatings in ATS will demonstrate "prime reliability;" i.e., they will be deposited and used in a way that will provide protection for the entire life of the component. This program also seeks to identify non-destructive inspection techniques that can be used to verify initial coating quality and to determine residual life remaining on engine service components.

\section{Future Activity}

The University of Connecticut has assembled a strong, knowledgeable team with a wealth of gas turbine engine and thermal barrier coating experience to conduct this program. The team consists of University investigators (University of Connecticut, University of California-Santa Barbara, University of California - Los Angeles, Ecole Polytechnique (Montreal), ATS engine developers (Allison Engine, General Electric, Solar Turbines, TurboPower and Marine, and Westinghouse Electric), coating manufacturers (Howmet Corporation and Pratt \& Whitney), National Laboratories conducting TBC research (Oak Ridge National Laboratory, NASA-Lewis Research Center, and Argonne National Laboratory) and AGTSR member universities 
performing TBC research (Georgia Tech, Lehigh, Penn State). In addition, this program is structured to strongly contribute to the educational goals of ATS by providing industrial engine and TBC research experience to a number of graduate students.

The program was initiated September, 1995. Figure 15 shows the program schedule. The nine techniques for evaluating bond strength and stress will be evaluated in the first year. The best methods will be selected. In the second and third year the selected measurement techniques will be optimized and quantitative measurements of bond stress and strength will be obtained as a function of simulated engine cycles.

\section{Acknowledgments}

This research is sponsored under a subcontract from the South Carolina Energy Research and Development Center. We appreciate the interest and guidance of Dr. Daniel Fant, the AGTSR Program Manager.

Phase I

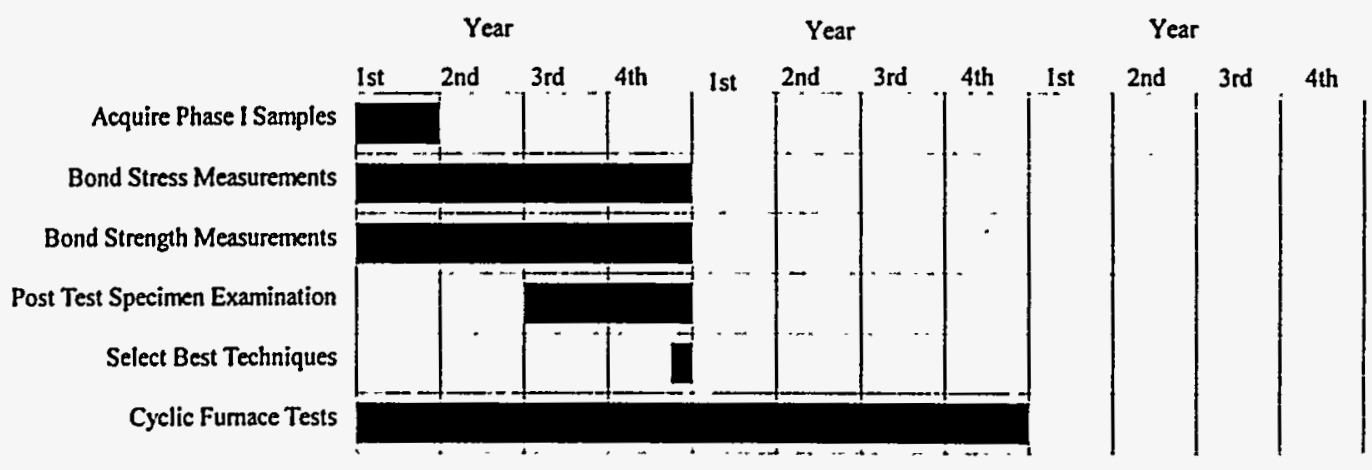

Phase II

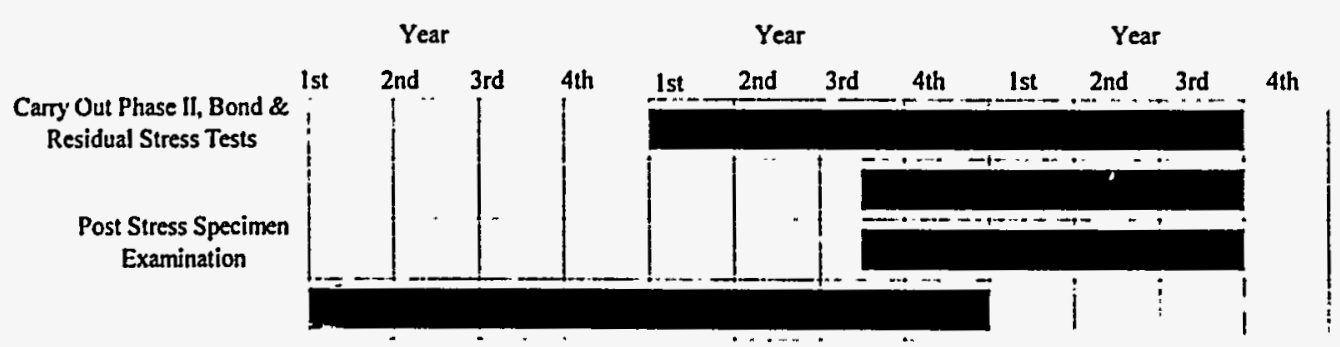

Phase III

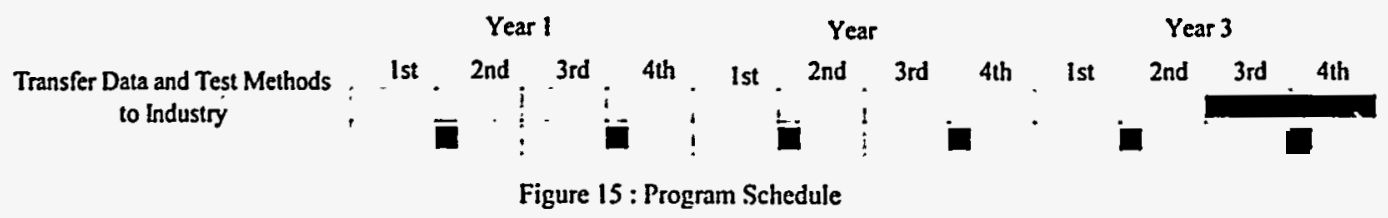




\section{References}

1. Meier, S. Manning, D. K. Gupta and K.D. Sheffler, "Ceramic Thermal Barrier Coatings for Commercial Gas Turbine Engines," JOM, 50-53, March 1991.

2. Hillery, R. V., and B. H. Pilsner, "Thermal Barrier Coating Life Prediction: Second Annual Report," NASA CR-179504, General Electric Company, 1986.

3. Strangman, T. E., J. Neumann and A. Liu, "Thermal Barrier Coating Life-Prediction Model Development Second Annual Report," NASA CR-179507, Garrett Turbine Engine Company, 1986.

4. Meier, S. M., D. M. Nissley and K.D. Sheffler, "Thermal Barrier Coating Life Prediction Model Development: Phase IIFinal Report," NASA CR-189111, Pratt \& Whitney, 1991.

5. Miller, R. A., and C. E. Lowell, "Failure Mechanisms of Thermal Barrier Coatings Exposed To Elevated Temperatures," Thin Solid Films, 99, p.265, 1982.

6. Gell, M., D. N. Duhl, D. K. Gupta and K.D. Sheffler, "Advanced Superalloy Airfoils," JOM, p. 11, July 1987.

7. Smialek, J. L., D. T. Jayne, J. C. Schaeffer and W. H. Murphy, "Effects of Hydrogen Annealing, Sulfur Segregation, and Diffusion on the Cyclic Oxidation Resistance of Superalloys: A Review," Thin Solid Films, 253, p. 285, 1994.

8. Ritter, J. E., "Crack Propagation in Ceramics", in Engineering Materials Handbook, vol. 4, Ceramics and Glasses, ASM International, p 694, 1991.

9. ' DeMasi, J. T., Sheffler, K. D. and Ortiz, M., "Thermal Barrier Coating Life Prediction Model Development," NASA CR 182230, 1989.
10. Canistraro, H. A., Jordan,E. H. , and Pease, D. M. 1992. "X-ray Based Displacement Measurement For Hostile Environments," Experimental Mechanics, 32, vol 4, p 289.

11. Geogopoulos, P. and Cohen, J. B., "Residual Stress Measurement of a Plasma Sprayed Coating Using Synchrotron X-ray Radiation," Materials Science and Engineering, 80, p L41, 1986.

12. Ma, Qing and Clarke, D. R. , "Stress Measurement in Single-Crystal and Polycrystalline Ceramics using their Optical Flourescence" J. of Am. Ceram. Soc. , Vol 76, p 1433, 1993.

13. Kupperman, D.S., Majumdar, J.P., and Singh, J.P., "Neutron Diffraction NDE for Advanced Composites," J. Eng. Mat. and Tech., 112, p 198, 1990.

14. Dai, Y. Marchand, N. J. and Hongoh, M., "Study Of Fatigue Crack Initiation and Growth In Titanium Alloys Using ACPD technique," Canadian Aeronautics and Space Journal, n.1, vol 39, p 35, March 1993.

15. Marchand, N. J. Dorner, W. and Ilschner, B., "A Novel Procedure to Study Crack Initiation and Growth in Thermal Fatigue Testing," ASTM STP 1060, p. 237,1990.

16. DeMasi, J. T., Sheffler, K. D. and Ortiz, M., "Thermal Barrier Coating Life Prediction Model Development," NASA CR 182230 1989.

17. Han, W. Rybicki, E. F. and Shadley, J. R. , "Bond Strength Testing of Thermal Spray Coatings Using ASTM C633-79: Effect of Specimen Size on Test Results," Thermal Spray: International Advances in Coatings Technology, Proceedings of the International Thermal Spray Conference, ASM International, p.911, 1992.

18. Gupta, V. Argon, A. S. , Cornie, and Parks, D. M., Mater. Sci. Eng. A 126, p.105.(1990) 
19. Cornie, J. A. Argon, A. S. , Gupta, V "Designing Interfaces in Inorganic Matrix Composites," MRS Bulletin, p 32 April 1991.

20. Guiberteau, F., Padture, N. P. and Lawn, R., "Effect of Grain Size on Hertzian Contact Damage in Alumina," J. of Am. Cer. Soc. Vol. 77, p. 1825, 1994.

21. Shaw, L. and R. Abbaschian, "A Test Specimen for Characterizing the Fracture Energy of Interfaces in Composites", in Control of Interfaces in Metal and Ceramics Composites, edited by R. Y. Lin and S. G. Fishman, A Publication of TMS, p 211, 1994.
22. Shaw, L., D. Miracle and R. Abbaschian, "Microstructure and Mechanical Properties of Metal/Oxide and Metal/Silicide Interfaces", Acta Metall. Mater., in press 1995.

23. Suo, Z. and J. W. Hutchinson, "Sandwich Test Specimens for Measuring Interface Crack Toughness," Mater. Sci. Eng., A107, p 135, 1989. 